\section{El desafío de la verdad al diálogo interreligioso*}

\author{
Carlos Miguel Gómez**
}

RECIBIDO: 11-11-16. APROBADO: 25-04-17

\begin{abstract}
Resumen: Este artículo defiende la posibilidad de evaluar la verdad de las posturas presentadas en el diálogo interreligioso como una de sus condiciones de posibilidad. Con esto se separa de las teorías del diálogo que pretenden formular criterios argumentativos, pragmáticos o éticos dejando en suspenso la pretensión de verdad de las religiones. En la primera parte se explora el lugar de la verdad en el diálogo; en la segunda se analizan las características de las pretensiones de verdad religiosa y sus diferencias con otros tipos de verdad; finalmente, se proponen dos criterios para evaluar la verdad en un diálogo interreligioso basados en la función dadora de sentido de las religiones y en el carácter relacional e histórico de la verdad religiosa.
\end{abstract}

Palabras clave: Diversidad religiosa; criterios para el diálogo interreligioso; verdad religiosa.

\section{The Challenge of Truth to Interreligious Dialogue}

Aвstract: This paper argues that the evaluation of religious truth claims is one of the conditions for the possibility of interreligious dialogue. This thesis takes distance from the theories that, bracketing the truth of religious claims, suggest that it is enough with argumentative, pragmatic or ethical criteria for making dialogue possible. Firstly, it explores the role of truth in dialogue; then it analyses the features and functions of religious truth claims, showing its differences with regard to other types of truth. The last part presents two criteria to evaluate the truth of religious claims in dialogue-one based on the meaning-giving function of religion, and the other on the historical and relational character of religious truth.

KeYwORDs: Religious diversity; Normative elements of interreligious dialogue; Religious truth.

PARA CITAR ESTE ARTÍCULO:

Gómez, Carlos Miguel. "El desafío de la verdad al diálogo interreligioso". Theologica Xaveriana 185 (2018): 1-23. https:// doi.org/10.11144/javeriana.tx68-185. dvdi

\footnotetext{
* Una versión preliminar de este trabajo fue presentada en el Congreso Internacional de Teología, "Interpelaciones del papa Francisco a la teología hoy", Pontificia Universidad Javeriana, 2016. El artículo hace parte del programa de investigación sobre las condiciones de posibilidad del diálogo interreligioso en el que he venido trabajando a lo largo de la última década.

** Ph.D. Religionsphilosophie, Goethe Universität-Frankfurt. Profesor asociado y director del Centro de Estudios Teológicos y de las Religiones, Cetre, Escuela de Ciencias Humanas, Universidad del Rosario, Bogotá. ORCID 0000-0001-6806-7058. Correo electrónico: carlos.gomezr@urosario.edu.co
} 


\section{Introducción}

Una de las características comunes de la reflexión de las últimas décadas sobre la diversidad religiosa y el diálogo entre tradiciones es la tendencia a poner entre paréntesis la pretensión de verdad de las religiones. En efecto, dicha tendencia desborda el ámbito de la filosofía de la religión y de la teología, y bien puede comprenderse como un signo de nuestro tiempo. Parece haber una suerte de consenso tácito según el cual, para poder vivir en un mundo plural, reconociendo la diferencia y evitando imponer el propio punto de vista sobre los demás, es necesario matizar toda pretensión de verdad. La verdad, en este sentido, para muchos es un concepto que debe ser transformado, cuando no simplemente superado, para hacer posible la democracia ${ }^{1}$.

En sentido inverso, el pluralismo religioso y cultural del mundo contemporáneo es interpretado como un periodo en el que ya no es posible hacer legítimamente afirmaciones con pretensión de universalidad y verdad, dada la redoblada conciencia de la historicidad y particularidad de toda tradición, de todo punto de vista, de toda teoría y visión de mundo². Incluso si la afirmación de la diversidad no implica necesariamente el relativismo, pues siempre es posible encontrar criterios para evaluar afirmaciones heterogéneas sin recurrir al criterio de verdad (por ejemplo, criterios pragmáticos, éticos, contextuales, etc.), de manera interesante, las teorías del diálogo que procuran buscar criterios de otro tipo para hacer posible la comunicación y la crítica intercultural suelen basarse en teorías de la argumentación que requieren la suspensión de la evaluación de la verdad de las religiones³.

En este artículo defenderé la tesis según la cual el diálogo interreligioso solo es posible sobre la base de una comprensión apropiada de la pretensión de verdad religiosa. Sin ella, no se hace justicia a los interlocutores en el diálogo, y no se puede en realidad respetar al otro ni dejarse interpelar por la alteridad de sus posiciones.

\footnotetext{
${ }^{1}$ Rorty, Contingencia, ironia y solidaridad, 86.

2 Panikkar, The Intrareligious Dialogue, 23.

${ }^{3}$ Este es el caso de mi libro Interculturality, Rationality and Dialogue. In Search for Intercultural Argumentative Criteria for Latin America (2012), en el cual desarrollé una teoría de la argumentación basada en criterios normativos para evaluar las posturas presentadas en un diálogo intercultural. Una de las presuposiciones de este trabajo consiste en que es posible (e incluso necesario) desarrollar una teoría del diálogo interreligioso de modo independiente de una teoría sobre la verdad de las religiones. Si bien esto posibilita un procedimiento dialógico capaz de evaluar y decidir entre posturas rivales en un diálogo con miras a viabilizar procesos de deliberación intercultural en una sociedad pluralista, constituye también una limitación severa de los fines y tareas del diálogo. Adicionalmente, dejar entre paréntesis la pregunta por la verdad impide la comprensión adecuada de la diversidad religiosa y del potencial de las religiones para participar en la construcción de sociedades realmente pluralistas. En este artículo pretendo comenzar a subsanar tales deficiencias.
} 
¿Cómo es posible alcanzar la comprensión de la verdad religiosa que necesitamos para el diálogo? Esta tarea ha de ser realizada mediante una investigación filosófica que articule dos momentos argumentativos: uno analítico y otro normativo. Así, partiremos del análisis y la elucidación del concepto de verdad. Para esto, en la primera parte procuraré mostrar que reconocer que los interlocutores realizan afirmaciones con pretensiones de verdad que deben ser examinadas y evaluadas como tales es un presupuesto necesario para que la práctica del diálogo interreligioso pueda realizarse, en particular, de cara a las tareas que comúnmente se le atribuyen. Con esto, captaremos primero la verdad desde el punto de vista formal propio de las presuposiciones pragmáticas del diálogo. Sin embargo, esto no es suficiente. Por ello, en la segunda parte es necesario dar el paso hacia la caracterización del modo propio de ser de las pretensiones de verdad religiosas, para diferenciarlas de otras pretensiones de verdad, en particular, de la científica.

El resultado de este primer momento ha de ser una comprensión apropiada del concepto de verdad que nos permita formular la pregunta fundamental sobre cómo es posible evaluar las pretensiones de verdad religiosa que se enfrentan en un diálogo. Este primer momento analítico sobre el concepto de la verdad se situará en el contexto particular de la reflexión de la teología y la filosofía de la religión actuales, tanto como del desarrollo gradual de la comprensión de la necesidad y finalidad del diálogo por parte de la Iglesia Católica.

A partir de ahí, el segundo momento de la investigación indagará por los criterios para evaluar la verdad de las religiones en el diálogo. En diálogo con el pensamiento teológico de Alister McGrath y Wolfhart Pannenberg sugeriré dos criterios epistemológicos que permiten examinar y evaluar la verdad de las afirmaciones presentadas en un diálogo interreligioso: uno relacionado con la posibilidad de valorar la capacidad dadora de sentido de las afirmaciones religiosas y el otro orientado a comprobar la conciencia histórica de los interlocutores.

Dado que estos dos criterios se basan claramente en una comprensión cristiana de la historia y del carácter relacional de la verdad, en la conclusión defenderé que no solo es legítimo sino necesario construir criterios normativos para el diálogo basados en la autocomprensión propia de cada tradición participante, sin que ello suponga que tales criterios deban ser aceptados o utilizados por los interlocutores pertenecientes a otras tradiciones. Por el contrario, también ellos deben asumir la tarea de proponer sus propios criterios a partir de sus sistemas religiosos. 


\section{El problema de la verdad en el diálogo interreligioso}

Para comprender el lugar de la verdad en el diálogo y por qué buscar la comprensión adecuada de la verdad propia y la de los interlocutores es una condición necesaria para dialogar, es importante partir de la clarificación de sus propósitos y dimensiones. Al respecto consideremos la siguiente indicación iluminadora de Aparecida:

El diálogo interreligioso, además de su carácter teológico, tiene un especial significado en la construcción de la nueva humanidad: abre caminos inéditos de testimonio cristiano, promueve la libertad y dignidad de los pueblos, estimula la colaboración por el bien común, supera la violencia motivada por actitudes religiosas fundamentalistas, educa a la paz y a la convivencia ciudadana: es un campo de bienaventuranzas que son asumidas por la doctrina social de la Iglesia. ${ }^{4}$

Según este párrafo, el diálogo interreligioso por lo menos debe contribuir en tres tareas:

1. Enriquecer nuestra comprensión teológica, lo cual implica esforzarse por discernir las creencias y prácticas de los otros en sus propios términos, tanto como profundizar en la propia religión. Esto es posible gracias a que el encuentro con los diferentes ofrece una especie de medio de contraste para ver mejor lo propio y nos exige reinterpretar lo que creemos, de modo que pueda responder a los retos que los otros nos plantean.

2. El diálogo debe ofrecer un nuevo medio de testimonio cristiano, de modo que este no se opone al anuncio del Evangelio, sino que permite hacerlo de un modo diferente, ofreciendo, por ejemplo, un signo de nuestra capacidad de convivir con los otros, amando a los diferentes y buscando el bien común.

3. Finalmente, el diálogo debe constituir un mecanismo para la construcción de sociedades más justas, lo cual solo puede llevarse a cabo hoy en día integrando diversos modos de comprender los problemas comunes (pobreza, injusticia, violencia, crisis ecológica) y buscando recursos para su solución en diferentes tradiciones.

Ahora, la preocupación por la verdad no es solo esencial en lo que respecta a las discusiones teológicas. Sin ella es imposible que el diálogo lleve a cabo alguna de estas tareas; más aún, ninguna práctica comunicativa puede considerarse propiamente un diálogo si excluye de ella la cuestión de la verdad. Si se considera que no hay verdad en las otras tradiciones, ¿qué sentido tendría dialogar con ellas? Por otro lado, si se parte del supuesto según el cual todas las tradiciones son igualmente verdaderas o

\footnotetext{
${ }^{4}$ Celam, V Conferencia del Episcopado Latinoamericano y del Caribe. Documento de Aparecida 239.
} 
se asume que no es posible evaluar la verdad de lo que decimos en el diálogo, dejaríamos de tomar en serio a las tradiciones participantes, que realizan afirmaciones que pretenden ser verdaderas, y por esto nos haríamos incapaces de comprometernos suficientemente con la búsqueda común a la que nos invita el diálogo.

Un sincretismo conciliador sería en el fondo un totalitarismo de quienes pretenden conciliar prescindiendo de valores que los trascienden y de los cuales no son dueños. La verdadera apertura implica mantenerse firme en las propias convicciones más hondas, con una identidad clara y gozosa, pero "abierto a comprender al otro" y "sabiendo que el diálogo realmente puede enriquecer a cada uno". ${ }^{5}$

Ciertamente, para que el diálogo interreligioso sea posible, es necesario tener una particular disposición hacia los otros que se basa en buena parte en el modo como su verdad, tanto como la propia, son comprendidas. En este sentido, sigue siendo válida la crítica a las denominadas posturas exclusivistas, según las cuales solo hay verdad y potencial de salvación en una tradición religiosa (por lo general, aunque no necesariamente, aquella a la que pertenece quien afirma esta posición) ${ }^{6}$.

Si no se puede reconocer que en la otra tradición hay algo verdadero, algo que se puede aprender y que puede enriquecer el punto de vista propio, un verdadero diálogo es imposible. En estos casos, las formas comunicativas que predominan son las del adoctrinamiento, la enseñanza unidireccional, la prédica y otras semejantes`. En una palabra, el diálogo interreligioso es una práctica comunicativa que exige una particular disposición de los participantes y se basa, en buena parte, en su comprensión de la verdad. ¿Cuál debe ser pues esta comprensión de la verdad religiosa que puede hacer posible el diálogo?8

${ }^{5}$ Francisco, Exhortación apostólica "Evangelii gaudium"251. Los textos entre comillas son de Juan Pablo II, Redemptoris missio 56.

${ }^{6}$ La doctrina de Extra Ecclesiam nulla salus es un claro ejemplo de esta posición. Algunos afirman que la Iglesia Católica no la afirma ya más, después del Concilio Vaticano II. Sin embargo, esto es discutible. “¿Cómo entender esta afirmación tantas veces repetida por los padres de la Iglesia? Formulada de modo positivo significa que toda salvación viene de Cristo-cabeza por la Iglesia que es su cuerpo" (Iglesia Católica, "Catecismo de la Iglesia Católica" 846).

${ }^{7}$ Gómez, Diálogo interreligioso: el problema de su base común, 26.

${ }^{8}$ Para la exploración detallada sobre la discusión actual en la teología de las religiones en torno de los ya clásicos modelos el exclusivismo, el inclusivismo y el pluralismo, ver a Teixeira, Teología de las religiones. Una visión panorámica, 36-71. La segunda parte de este libro y el capítulo VIII de la obra de Tamayo, Fundamentalismos y diálogo entre religiones, ofrecen un examen detallado de las repercusiones y discusiones al interior de la Iglesia Católica en torno de la diversidad religiosa y del diálogo, en el siglo XX, desde una perspectiva histórica que no podemos reconstruir aquí. 
Como es sabido, las denominadas posturas inclusivistas procuran dar un paso hacia adelante en el reconocimiento de la verdad del otro, el cual, sin embargo, no parece suficiente. Para estas posturas, que resultan dominantes en la mayoría de las denominadas "grandes religiones del mundo", en la actualidad, hay verdad y salvación en las otras religiones, pero estas dependen de la manifestación plena de la verdad en la propia tradición.

Como expresa la constitución Gaudium et spes 57: "El Verbo de Dios [...] antes de hacerse carne para salvarlo todo y recapitular todo en sí estaba ya en el mundo como la verdadera luz que ilumina a todos los hombres". Por eso, la obra salvadora de Cristo, que responde a la voluntad de salvación universal del Padre, tiene lugar antes de la aceptación y difusión de su mensaje, y rebasa la labor evangelizadora de la Iglesia. El Espíritu de Cristo, que actúa en la creación entera, la cual está dirigida hacia él $(E f$ 1,10), está presente en todos los seres humanos de todos los tiempos. En tanto que es "la luz verdadera que ilumina a todo hombre" (Jn 1,9), actúa también en las otras religiones, en donde ha ido sembrando las "semillas del Verbo". Estas semillas, o "destellos de luz" son los elementos de verdad y el potencial soteriológico que permiten a los fieles de otras religiones reconocer -en el mundo y en sus vidas- la presencia de lo divino. La declaración de Nostra aetate 2 es célebre en este sentido:

La Iglesia Católica no rechaza nada de lo que en estas religiones hay de santo y verdadero. Considera con sincero respeto los modos de obrar y vivir, los preceptos y doctrinas que, por más que discrepen en mucho de lo que ella profesa y enseña, no pocas veces reflejan un destello de aquella verdad que ilumina a todos los hombres.

Lo que hace de esta una postura inclusivista reside en que la presencia del Espíritu en las otras religiones "no se produce con independencia de Cristo y de su Iglesia. Se funda en la presencia universal del Espíritu, que no puede desligarse del misterio pascual de Jesús"'. Si bien se reconoce que hay verdad y salvación en las otras religiones, la presencia del Espíritu en ellas no puede equipararse con su presencia en la Iglesia de Cristo. Dado que hay una diferencia entre la semilla de algo y su realización completa, es necesaria la acción misionera de la Iglesia para discernir, utilizando el Evangelio como norma, cuáles elementos de las otras religiones son verdaderos y ayudan a la salvación, y cuáles no.

Si bien el inclusivismo es coherente con la pretensión de verdad de cada tradición particular, al no renunciar a lo que se considera central y definitorio de cada una, cobra un precio demasiado alto a los demás: al ser incorporados y reinterpretados

\footnotetext{
${ }^{9}$ Comisión Teológica Internacional, El cristianismo y las religiones, 81.
} 
como modos imperfectos de la verdad y caminos provisionales hacia la salvación (o la liberación, o la iluminación o el conocimiento), su originalidad y diferencia puede ser deformada y malinterpretada. En efecto, su alteridad es difícilmente escuchada si se la entiende como una suerte de ignorancia de su verdadera identidad y como una carencia de la religión superior ${ }^{10}$.

Por su parte, las denominadas posturas pluralistas que, desde mediados de la década de los 80 del siglo pasado, procuran superar el inclusivismo para hacer posible el diálogo, van demasiado lejos en su relativización de la pretensión de verdad. En esta familia de posiciones ya es célebre la "hipótesis pluralista" de John Hick:

Los grandes credos del mundo encarnan diferentes percepciones y concepciones, así como diferentes respuestas a lo real o lo definitivo, surgidas desde dentro de las principales formas culturales alternativas de ser humano; y dentro de cada una de las cuales manifiestamente tiene lugar el proceso de transformación de la existencia humana consistente en pasar del estar-centrado-en-sí-mismo al centrarse-en-la-realidad. Por lo demás, este proceso ocurre, hasta donde la observación humana puede decir, hasta el mismo punto en cada variable cultural. Así, las grandes tradiciones religiosas deben considerarse como "espacios" soteriológicos alternativos. ${ }^{11}$

Para Hick, el pluralismo implica la igual validez de las diferentes tradiciones, tanto en términos epistemológicos (es decir, en lo que respecta a la verdad de sus afirmaciones sobre la realidad suprema, su relación con el mundo y el sentido y destino de la vida humana), como soteriológicos (es decir, en cuanto a la posibilidad de conducir a, como él mismo suele escribir, la "salvación/liberación/iluminación/plenitud").

Aquí no podemos detenernos a examinar con detalle los problemas que genera el modo como Hick fundamenta su hipótesis pluralista a partir de una reinterpretación de la filosofía teórica de Kant, según la cual lo divino tiene carácter nouménico y toda experiencia religiosa es siempre parcialmente constituida por las categorías propias de una cultura y un tiempo determinados ${ }^{12}$. Nos interesa ver cómo el pluralismo implica un replanteamiento de la pretensión de verdad de las religiones, en el sentido de que ningún concepto de lo divino, así como ninguna doctrina o relato sagrado, en tanto que son, al menos en parte, productos históricos, pueden aspirar a expresar plenamente el modo de ser de aquello de lo que hablan ${ }^{13}$.

${ }^{10}$ Gilkey, "Pluralism and its theological implications", 42; Coward, Pluralism. Challenge to World Religions, 38.

${ }^{11}$ Hick, Problems of Religious Pluralism, 36.

${ }^{12}$ Para un tratamiento detallado ver a Hick, An Interpretation of Religion, 233ss., y a Gómez, Diálogo interreligioso, 50ss.

${ }^{13}$ Este tipo de pluralismo es particularmente problemático para la autocomprensión cristiana, en cuanto parece relativizar las creencias de que Jesucristo es el único y absoluto mediador entre Dios y los seres 
Sin duda, esta manera de comprender la relación entre historicidad y verdad es característica de la autocomprensión de la situación intelectual del presente; pero creo que aquí radica un problema no resuelto adecuadamente ${ }^{14}$. Se ha convertido casi en un presupuesto epistemológico contemporáneo la idea según la cual, dado que todo conocimiento es siempre cultural e históricamente situado, esto es, en cuanto implica la utilización del lenguaje y los instrumentos culturales de una época o cultura y no puede desligarse de los intereses, valores y necesidades de un grupo humano particular, entonces no puede ser verdadero ni falso respecto de cómo sea el mundo.

Por el contario, la verdad y la falsedad se definen exclusivamente como funciones sociales, culturales, políticas o -en todo caso- como criterios internos al sistema discursivo que los produce. En el caso de las religiones, dado que no hay forma de referirse a lo divino (o a cualquier otra cosa que se refiera-si lo hace- el lenguaje religioso), independientemente de un lenguaje y un sistema conceptual o cosmovisional, y todo sistema es histórico y culturalmente determinado, entonces (así reza el argumento), ningún sistema de creencias se encuentra en mejor posición para validar su pretensión de verdad y, por tanto, todos parecen ser igualmente válidos (o inválidos).

La consecuencia directa de este tipo de posición es "la indiferencia, es decir [...] no tomar en serio la pretensión de verdad tanto propia como ajena" ${ }^{15}$. En esta situación, sigue siendo urgente la pregunta de cuál es el modo apropiado de comprender la pretensión de verdad religiosa, tanto de la propia tradición como de la de los otros. Esta tarea es la condición de posibilidad para el diálogo entre las religiones, y en general para el diálogo de las religiones con la cultura contemporánea, particularmente con la ciencia, cuya pretensión de verdad tiende a ser vista en nuestra cultura como inmediatamente válida y, muchas veces, totalizante.

El lugar de las religiones en la esfera pública, su capacidad de tener algo relevante que decir a la sociedad y al mundo contemporáneo, depende en gran medida de que logremos comprender en qué consiste su pretensión de verdad y cómo se relaciona con las pretensiones análogas de otras tradiciones y formas de saber.

humanos, y de que su encarnación constituye la revelación más plena y definitiva de Dios, expresada en el Nuevo Testamento. Varios trabajos ya célebres, de teólogos cristianos contemporáneos, pretenden solucionar esta cuestión mediante la reinterpretación del significado de la universalidad de la acción salvífica de Jesucristo y de la historicidad de la revelación, que permite captarla como un acontecimiento progresivo, abierto y diferenciado. Es de resaltar aquí el muy influyente y discutido libro de Jacques Dupuis, Hacia una teología cristiana del pluralismo religioso.

${ }^{14}$ Para examinar otras críticas a la hipótesis pluralista de Hick, puede verse s D’Costa (ed.), Christian Uniqueness Reconsidered, y a Twiss, "The Philosophy of Religious Pluralism: A Critical Appraisal of Hick and His Critics".

${ }^{15}$ Comisión Teológica Internacional, "El cristianismo y las religiones", 96. 


\section{¿En qué consiste la pretensión de verdad religiosa y cómo se relaciona con otras pretensiones de verdad?}

Para contestar adecuadamente esta pregunta, en primer lugar, es importante limpiar el terreno de dos interpretaciones comunes en nuestra situación intelectual acerca de la pretensión de verdad de las religiones. La primera es la idea según la cual el lenguaje religioso carece de valor cognitivo, es decir, que no afirma nada sobre la realidad (divina o humana), ni da ningún tipo de conocimiento, sino más bien cumple otras funciones; por ejemplo, la de generar vínculos comunitarios, expresar sentimientos y emociones, o producir utopías.

Esta posición ha sido particularmente defendida por algunos filósofos de la religión quienes, al seguir al segundo Wittgenstein, han pretendido rescatar el valor y la importancia de la religión de las objeciones de quienes, influenciados aún por el positivismo lógico, sostenían que las afirmaciones religiosas simplemente carecen de sentido porque no pueden ser verificadas empíricamente. La postura de D. Z. Phillips ofrece un ejemplo claro de esta posición:

Las creencias y las prácticas religiosas son [...] expresiones de lo que afecta profundamente la vida de las personas. El hecho de que alguien afirme que sus desgracias se deben a que deshonró los espíritus de guerreros muertos en batalla es de suyo la forma que esa profundidad adquiere en este caso; es una expresión de lo que la muerte significa para esta persona y los demás junto a quienes vive. Que un hombre diga que Dios cuida de él a través de todas las cosas es una expresión de los términos en los cuales enfrenta y da sentido a las contingencias de la vida. ${ }^{16}$

Según está posición, una frase como "gracias, Dios mío, por estos alimentos", incluso cuando es pronunciada por un creyente, no implica la afirmación de la existencia de Dios y podría traducirse por algo como "qué bueno que tengo comida", o "me gustaría que nunca me faltara el alimento" y cosas parecidas. Evidentemente, tal interpretación del leguaje religioso es muy problemática porque falla en reconocer lo que los creyentes en realidad dicen. Por eso mismo, este tipo de teorías -que bien pueden denominarse "emotivistas"- permiten ver hasta qué punto el lenguaje religioso no puede nunca comprenderse si se excluye la pretensión de verdad, es decir, la intención de afirmar algo sobre lo real.

Si bien el lenguaje religioso cumple muchas funciones que no pueden reducirse a lo cognitivo (agradecer, suplicar, pedir perdón, alabar), todas ellas presuponen

${ }^{16}$ Phillips, Religion Without Explanation, 36, citado por Woltersttorf, "Are Religious Believers Committed to the Existence of God?", 353. 
ciertas afirmaciones sobre lo real: del mismo modo que cuando pido perdón a un amigo presupongo que existe, que lo he ofendido, que me puede perdonar, etc. De hecho, la aspiración a señalar, así sea metafóricamente hacia la realidad suprema, aquello de lo cual todo lo demás depende, representa el corazón de lo que puede denominarse una creencia religiosa ${ }^{17}$. En una palabra, el lenguaje religioso no funciona si extraemos de él su pretensión de verdad.

¿Acaso las afirmaciones de las religiones sobre lo real son iguales a las de las ciencias o el sentido común? ¿Hay algo radicalmente distinto en el lenguaje religioso? Esto nos lleva a la segunda posición sobre la verdad de las religiones que -a mi modo de ver- también es inadecuada. Se trata de la idea de que las ciencias y las religiones hablan de cosas tan diferentes, y lo hacen según métodos y estilos tan distintos, que se trata de dominios completamente independientes, los cuales no entran en conflicto ni pueden dialogar entre sí.

Ciertamente, la aclaración de Galileo -"la Biblia enseña cómo llegar al cielo y no cómo funciona el cielo" - continúa siendo válida y pertinente, en cuanto evita los falsos conflictos que generan tanto el literalismo en la interpretación de los libros sagrados como la idea típica de las críticas de la religión, desde finales del siglo XIX, que la ven como la ciencia del hombre primitivo. No obstante, mantener clara la diferencia de propósitos y funciones de la ciencia y la religión no puede significar diluir la aspiración de las religiones a ofrecer una visión coherente de la realidad que pueda dar cuenta de la relación entre el modo de ser del mundo y lo divino.

En efecto, semejante aspiración es el centro de la pretensión de verdad religiosa y lo que la diferencia de las hipótesis científicas. Mientras que las ciencias buscan explicar ciertos fenómenos particulares, mostrando el entramado de relaciones causales que los producen de acuerdo con leyes universales, las religiones establecen un marco de sentido global, una suerte de contexto total que da coherencia a toda experiencia posible $^{18}$.

Esto no significa, por supuesto, que las religiones ofrezcan una suerte de teoría del todo, en el sentido de un sistema de proposiciones susceptible de explicar cada fenómeno particular, sino más bien que brindan, mediante símbolos, imágenes y relatos, un contexto narrativo que establece maneras de ver y de vivir susceptibles de ser aplicadas a la totalidad de lo real ${ }^{19}$.

\footnotetext{
${ }^{17}$ Hick, An Interpretation of Religion, 236.

${ }^{18}$ Clayton, Explanation from Physics to Theology, 130-131.

${ }^{19}$ Gómez, "Fe y conocimiento".
} 
Aún más, la capacidad de la creencia religiosa de dar sentido es mejor comprendida si se la diferencia de las hipótesis científicas y de las proposiciones empíricas. Mientras que la verdad de estas últimas suele comprenderse como su capacidad de decir de modo adecuado cómo son los aspectos de la realidad de los que hablan, ningún enunciado religioso es bien comprendido como una descripción literal, pues es propio de gran parte de las tradiciones religiosas del mundo enfatizar en la trascendencia de lo divino, que no se deja apresar ni encerrar en conceptos y enunciados meramente discursivos.

Por eso, el carácter simbólico es uno de los rasgos propios de los enunciados religiosos que hacen que su verdad deba comprenderse en un sentido diferente del proposicional. ¿Cuál es este sentido de la verdad propio de los enunciados religiosos? Ante todo tiene que ver con su capacidad de captar y expresar simbólicamente un orden de sentido trascendente que determina las características básicas de la realidad y la dispone como un "mundo", que puede ser habitado por los seres humanos, lo cual no solo indica la naturaleza sino también el propósito de la existencia humana $y$ de la realidad en general ${ }^{20}$.

El problema consiste, por supuesto, en que mientras que la ciencia parece contar con métodos para decidir las disputas entre teorías rivales, la gran diversidad de imágenes religiosas del mundo parece contar como un argumento contra la pretensión de verdad de cada una de ellas. En efecto, este argumento ha sido comúnmente utilizado desde la época de Hume en contra de la religión, pues -en sus palabras- "en materia de religión, todo lo que es diferente es contrario" ${ }^{21}$.

Así, la presencia de diferentes descripciones sobre la naturaleza de la realidad última y del sentido y destino de la vida humana pareciera contar contra la verdad de todas las religiones. ¿No es una exigencia de la verdad algo así como la unidad del contenido de los enunciados que pretenden decir algo de lo real? ¿Cómo podemos entender y evaluar las afirmaciones rivales y en apariencia contradictorias de diferentes tradiciones religiosas?

Con estas preguntas entramos al corazón del problema de la verdad en el diálogo interreligioso. Hemos visto que las religiones no pueden renunciar a su pretensión de verdad si, por un lado, quieren mantenerse fieles a su aspiración fundamental de señalar

\footnotetext{
${ }^{20}$ Ver a Gómez, ““Fe y conocimiento. Investigación sobre la función epistémica de la creencia religiosa”. Para una exploración detallada de los modos como las creencias religiosas (y en particular la creencia de que el mundo es creado) establecen el orden de sentido previo necesario para el surgimiento y desarrollo de la ciencia natural moderna, ver la obra de Múnera, Meléndez y Gómez (eds.), Ciencia y creación. La investigación cientifica de la naturaleza y la visión cristiana de la realidad, que será publicada próximamente. ${ }^{21}$ Hume, Investigación sobre el entendimiento humano, 157.
} 
y poner en contacto con la realidad suprema, de la cual toda otra realidad depende; y por otro, si en el diálogo buscamos tomar en serio a los otros, es decir, escuchar lo que tienen que decir acerca de lo real.

A la vez, las diversas afirmaciones sobre lo divino, así como las distintas formas de vida y caminos para alcanzarlo parecen tan enormemente dispares y mutuamente contradictorias, que la conciencia de la diversidad religiosa suele generar dos tipos de reacciones: que cada uno se repliegue sobre su propia tradición negando a las demás, o que simplemente niegue la verdad de todas (incluso si esto se hace al afirmar que todas son simplemente igualmente verdaderas). Ninguna de estas dos respuestas es satisfactoria ni hace posible el diálogo.

En efecto, las tradiciones religiosas solo pueden pretender que tienen algo relevante que aportar al mundo contemporáneo si son capaces de relacionar sus contenidos cosmovisionales con los de los demás. Esto es particularmente importante para las religiones universalistas como el cristianismo, como afirma John Cobb con mucha claridad:

Es justamente en la medida en que una tradición pretende tener relevancia universal que su exclusión de las ideas de los otros es problemática en términos de su propia norma. Por supuesto que es posible seguir manteniendo la pretensión de validez universal al tiempo que se ignoran las pretensiones similares de los otros. Pero de esta manera permanece siendo una mera pretensión. Demostrar la validez de una pretensión requiere que las pretensiones de los otros sean comprendidas y que la relación entre ellas sea explicada. ${ }^{22}$

En este sentido, a diferencia de lo que algunos piensan, el pluralismo no exige la suspensión de la pretensión de verdad y la universalidad de las religiones. A la inversa, estas pretensiones requieren de escenarios pluralistas de discusión y confrontación para continuar siendo mantenidas. El diálogo interreligioso representa, en este sentido, un espacio privilegiado para el intercambio crítico de posiciones y razones, lo cual es, por supuesto, imposible, si no se cuenta con algo así como estándares mutuamente aceptados de evaluación de lo que creemos y hacemos. ¿Puede ofrecerse un criterio para evaluar la verdad de las posiciones religiosas presentadas en un diálogo interreligioso?

\section{¿Es posible evaluar en el diálogo interreligioso las pretensiones de verdad rivales?}

La búsqueda de criterios para evaluar posiciones contrarias es una de las características comunes de los trabajos sobre el diálogo interreligioso en las últimas décadas. No

${ }^{22}$ Cobb, "Beyond 'Pluralism”, 92. 
obstante, como señalamos en la introducción, buena parte de esta búsqueda ha implicado una suspensión del criterio de verdad o su desplazamiento hacia criterios de otro orden, en particular de tipo ético y político. Un ejemplo célebre de este desplazamiento es la propuesta de Paul Knitter, para quien la base común del diálogo debe ser un compromiso común con la promoción de lo que él denomina el bienestar ecohumano ${ }^{23}$.

Dado que la situación planetaria actual genera un contexto común, marcado por la opresión y la pobreza, tanto como por la devastación ambiental, la verdad del mensaje de las religiones - para Knitter- debe ser medida en relación con su capacidad de responder a los retos del presente promoviendo la liberación integral de los seres humanos y la Tierra.

La capacidad liberadora de las religiones es fundamental y no puede comprenderse su pretensión de verdad de forma desconectada de su potencial salvífico, la cual, para un gran número de ellas, comienza en este mundo aunque no puede alcanzar su realización definitiva aquí; pero -a mi modo de ver- este tipo de criterio es insuficiente para dar cuenta de la verdad religiosa, pues esta genera, como hemos dicho, además de formas de vida y cursos de acción, un marco total de interpretación que debe ser capaz de hacer coherente la diversidad y complejidad de nuestras experiencias.

¿Qué implica establecer un criterio de verdad para las tradiciones religiosas? Considero que esta tarea implica al menos responder a dos retos: (1) El de la "evaluación" de los enunciados religiosos de cara a otro tipo de enunciados, como los de la ciencia y los de otras tradiciones; y (2) dar cuenta del carácter histórico de todo enunciado religioso y mostrar qué implicaciones tiene esto para la comprensión adecuada de la pretensión de verdad de las religiones.

Para terminar, quisiera realizar algunas anotaciones sobre estos dos aspectos, las cuales deben ser ampliadas y perfeccionadas.

1. El problema de la "evaluación" representa una de las grandes dificultades para comprender la verdad de las religiones. Evaluar una pretensión de verdad, en el sentido más básico, implica algún tipo de validación, verificación o contrastación de una afirmación con la realidad que pretende describir. En el caso de las afirmaciones religiosas, como indicamos antes, dado que su objeto transciende el ámbito de la experiencia empírica, pues se trata de la realidad última o, en todo caso, de realidades que no pueden reducirse a objetos de la experiencia corriente, su verificación parece imposible; pero simplemente encerrarse sobre la propia tradición y renunciar a toda posibilidad de examinar críticamente su verdad -como sugieren algunas

\footnotetext{
${ }^{23}$ Knitter, One Earth Many Religions: Multifaith Dialogue and Global Responsibility, 181.
} 
posturas radicalmente fideistas- equivale a retraer esta tradición del espacio público y renunciar a dialogar, no solo con las personas de otras tradiciones, sino en general con la cultura y la sociedad.

Por otra parte, una solución como la de John Hick, según la cual los enunciados religiosos sí pueden ser verificados empíricamente, pero en la otra vida, resulta, por cierta que pueda ser, inútil para responder a los retos del presente. Los enunciados religiosos no pueden validarse en el mismo sentido que las proposiciones de las ciencias o del sentido común, pero esto no significa que no puedan ser comprobadas o evaluadas en absoluto. Si -como dijimos- su función epistémica es distinta de la de la ciencia, en cuanto no busca explicar los fenómenos, sino integrarlos en un marco de sentido que da unidad y coherencia a la experiencia y hace posible un modo de vivir, entonces es respecto de esta capacidad de dar sentido que la evaluación puede tener lugar.

Un procedimiento de este tipo es diferente al contraste entre un enunciado y los hechos, el cual busca verificar si estos han sido adecuadamente descritos (sea lo que sea que esto signifique $)^{24}$. Sin embargo, tiene algo en común con este: se trata de evaluar si un marco de sentido religioso es capaz de articular la diversidad y discontinuidad de la experiencia permitiendo captar su riqueza y dándole valor y propósito.

En efecto -como señala Pannenberg-, nuestras experiencias son dispares, siempre parciales y siempre incompletas. Estos fragmentos no se autointerpretan, ni son capaces de establecer, por sí solos, un todo coherente. En sí mismo, cada momento aislado de experiencia debe ser valorado y comprendido de cara a su pertenencia en una totalidad mayor ${ }^{25}$. El sentido de nuestras experiencias individuales, tanto como de nuestras actividades y descubrimientos (incluidos los descubrimientos científicos) depende de su referencia a algo que los desborda, a la que vez que los integra en un todo significativo. Esta especie de contexto total significativo es el que los relatos y las doctrinas religiosas pretenden establecer. En ellas, la diversidad de la experiencia es ordenada respecto de su relación con la realidad suprema.

Por eso, si bien no hay un acuerdo entre las religiones acerca de la naturaleza de la realidad última, al menos parece ser un rasgo común en las concepciones de lo divino comprenderlo como lo absolutamente real, aquello de lo que todo lo demás

\footnotetext{
${ }^{24} \mathrm{Si}$ bien tal procedimiento ha sido fuertemente cuestionado en la epistemología contemporánea, porque nunca podemos situarnos fuera de nuestro lenguaje y esquemas conceptuales para comprobar cómo este corresponde con una realidad no interpretada lingüísticamente (de modo que antes que verificar teorías, estamos solo en posición de falsearlas), la comprensión de la verdad como una relación de correspondencia parece inevitable para dar cuenta de lo que hacemos al hablar y, en general, del tipo de compromisos que generamos al hacer afirmaciones sobre el mundo.

${ }^{25}$ Pannenberg "Is There Any Truth in God-Talk? The Problem of Theological Statements from the Perspective of Philosophy of Science", 17.
} 
depende, al tiempo que es eso que constituye la aspiración fundamental y la meta última de la vida. En consecuencia,

...nada real puede ser adecuadamente comprendido en su particularidad sin referencia a Dios así entendido y, a su vez, es posible esperar que una comprensión profunda de la realidad sea posible solamente en relación con lo que se supone como realidad divina. ${ }^{26}$

Esto permite un primer criterio de evaluación de las afirmaciones religiosas en un contexto de diversidad de cosmovisiones y pretensiones de verdad: ¿Hasta qué punto permite una creencia religiosa (o un conjunto de ellas) integrar, haciendo inteligible, pero también dándoles valor y propósito, los diferentes fragmentos de nuestra experiencia, los cuales incluyen la presencia de teorías en apariencia rivales? En este sentido, tanto en ciencia como en religión, "la habilidad de iluminar la realidad es una medida importante de la confiabilidad de una teoría y un indicador de su verdad" ${ }^{27}$.

Según lo anterior, no todas las visiones de mundo tienen la misma capacidad para "iluminar la realidad", pues la experiencia puede resistirse a ciertas interpretaciones y, en general, sus fragmentos pueden no dejarse integrar fácilmente en un todo significativo. El que no haya experiencias puras, del todo desprovistas de interpretación, no significa que no hay nada más que interpretación en la experiencia, o que cualquier interpretación valga. Esto es así porque en la experiencia estamos abiertos y en relación con lo real, de modo que en ella se manifiesta algo que es diferente de nuestras operaciones intelectuales, de nuestros deseos, expectativas y necesidades.

En este sentido, la capacidad de las religiones de dar sentido propio no puede comprenderse simplemente como imposición o proyección de categorías meramente humanas sobre un mundo desordenado y en sí mismo carente de valor y significado. Por el contario, para que la articulación de la experiencia en una totalidad significativa sea posible, es necesario que lo que se da en la experiencia cotidiana, e incluso en la experiencia científica, de modo fragmentario y parcial, como una especie de señal o indicación, sea consistente con la totalidad de sentido que el lenguaje religioso busca expresar y que solo ha sido accesible a los seres humanos mediante la manifestación misma de lo divino.

Así, la capacidad de las religiones de dar sentido puede evaluarse respecto del éxito que tengan en integrar diferentes niveles y tipos de experiencia, de modo coherente con lo que se da en la experiencia (y no solo respecto de la coherencia interna del sistema de creencias o con su utilidad pragmática). Esto no significa que lo que

${ }^{26}$ Ibíd., 16.

${ }^{27}$ McGrath, Surprised by Meaning. Science, Faith and How We Make Sense of Things, 9. 
debe ser integrado como fragmentos de realidad y de experiencia descubiertos en otros ámbitos -como el científico- deba ceder su autonomía a la interpretación religiosa de la realidad.

Por el contrario, entre más rotundamente sea defendida la autonomía de la ciencia y de otras esferas del conocimiento y la cultura respecto de la religión, es decir, entre más claros y bien desarrollados (sin hacer uso explícito y directo de doctrinas religiosas) sean los criterios utilizados para validar lo que cuenta como un conocimiento válido en estas áreas, es más grande el reto de articularlos en un todo significativo. Porque las religiones no pueden pretender la imposición de los criterios de lo verdadero a otras disciplinas, sino más bien escuchar y estar atentas a sus resultados y aportes, para ver si sus doctrinas y símbolos fundamentales pueden ser reinterpretados para resonar de cara ellos ${ }^{28}$.

En este sentido, el éxito del conocimiento científico y la sofisticación argumentativas de las formas contemporáneas de racionalidad práctica en la moral y la política seculares pueden ser utilizadas, no para validar o refutar las creencias religiosas, sino como una suerte de indicador de su capacidad dadora de sentido.

2. Sin embargo, como nuestra experiencia es histórica, es decir, siempre abierta a nuevas posibilidades y nunca totalmente terminada, la eventualidad de articular su sentido en un todo mayor es también una tarea que nunca puede realizarse definitivamente.

Con esto llegamos al segundo reto que debe enfrentar la búsqueda de un criterio de verdad religiosa: evaluar la autoconciencia del carácter histórico de toda pretensión de verdad. Esta historicidad consiste en una tensión y un movimiento al que siempre está sometida una pretensión de verdad religiosa. Por un lado, toda pretensión de verdad religiosa implica una aspiración a la universalidad, pues si su objeto es la realidad absoluta, a partir de la cual es posible dar sentido a la diversidad de la experiencia, entonces no puede conformarse con ser solo una afirmación válida en un sector particular de lo real o para un solo grupo de personas. Por otro lado, la capacidad de dar sentido a nuevas experiencias solo puede realizarse parcialmente, progresivamente, y no puede darse nunca por enteramente realizada. Siempre hay algo más allá, algo posible y no articulado, algo que trasciende nuestro horizonte de comprensión, lo cuestiona y exige ser interpretado.

En el reconocimiento de esta tensión, que constituye la historicidad de la verdad, encontramos el segundo elemento de un criterio de verdad para el diálogo interreligioso. La capacidad de dar sentido a lo nuevo, a lo otro, exige apertura en

${ }^{28}$ McGrath, A Scientific Theology: Nature, 266ss. 
humildad y escucha a lo desconocido y lo diferente. La pretensión de verdad de un sistema de creencias solo puede validarse plenamente si es posible descubrir también en las nuevas experiencias, en las afirmaciones de los otros, una suerte de continuidad con las propias.

En este sentido -como afirma Pannenberg-, la verdad es lo que se confirma en el futuro ${ }^{29}$. No puede simplemente ser presupuesta respecto de las propias doctrinas o creencias, sino debe redescubrirse siempre en las nuevas experiencias y en el encuentro con los otros. Justamente por esto el diálogo interreligioso es un lugar de verdad: en contextos de diversidad religiosa y cultural como el nuestro, nadie puede pretender que sus creencias sean verdaderas sin haber pasado por la apertura, el contraste y la reinterpretación que requiere el diálogo interreligioso. Solo el encuentro con los otros nos hace conscientes tanto de la originalidad de la propia tradición y de su capacidad de ofrecer sentido a ámbitos cada vez mayores de la realidad, como de nuestras limitaciones, prejuicios y faltas de comprensión que empequeñecen la realidad para hacerla coincidir con nuestras preconcepciones.

Este segundo criterio de la verdad puede formularse en una pregunta como la siguiente: ¿Es capaz una tradición religiosa de mantenerse abierta a la transformación y al enriquecimiento mediante el encuentro con los otros? En este sentido, lo que podríamos denominar el "fanatismo con respecto a la propia pretensión de verdad", es decir, la pretensión de que una tradición posee la verdad completa y absoluta de modo ya plenamente realizado, es justamente una señal de que algunas de sus creencias fundamentales no pueden ser verdaderas. En el caso de las religiones, la humildad es una señal de la verdad.

No obstante, este segundo criterio es aún muy general y de difícil aplicación, pues no permite evaluar la verdad de creencias particulares. Se trata más bien de una especie de criterio para evaluar la actitud ante la verdad y no el contenido de las creencias. Ciertamente es útil y necesario, pero insuficiente. ¿Es posible relacionar la actitud que tenemos ante la verdad con el contenido mismo de nuestras creencias? Aquí encontramos una indicación importante sobre la naturaleza de la verdad religiosa. A diferencia de la verdad meramente proposicional de, por ejemplo, las teorías científicas, la verdad religiosa no consiste solo en una relación de correspondencia o adecuación (como quiera que esta sea entendida) entre los enunciados y la realidad.

Si bien este nivel proposicional de la verdad es constitutivo del lenguaje religioso, lo fundamental aquí no es solo describir cierto estado de cosas; en efecto, como dijimos, buena parte de eso a lo que se refiere el lenguaje religioso trasciende

\footnotetext{
${ }^{29}$ Pannenberg, "What is Truth?", 3 y 7.
} 
las capacidades de conceptualización y representación del lenguaje humano. Más bien se trata de señalar el camino, indicar hacia lo divino y señalar cómo puede ser alcanzado e integrado en una forma de vida.

Por eso, mientras que en el sentido proposicional el término "verdad" se refiere a un tipo de relación entre el lenguaje o la mente y el mundo (adaequatio rei et intellectus), en el sentido religioso más originario, la verdad es lo divino mismo. En este sentido, una creencia religiosa no es verdad, fundamentalmente, porque represente o describa adecuadamente lo divino, que está siempre más allá de toda representación o descripción, sino porque nos prepara y conduce a ello. Así, la verdad religiosa es siempre relacional y vivencial, mucho más que simplemente proposicional.

Consecuentemente, no se puede separar el contenido de nuestras creencias, es decir, lo que afirman de la actitud ante la vida y los otros que tenemos, así como de nuestra forma de vivir. No se trata aquí solo de la coherencia entre lo que creemos y hacemos, sino fundamentalmente de la coherencia entre lo que experimentamos en nuestra constante búsqueda de Dios y lo que de cara a esta experiencia podemos creer.

De este modo, la pregunta por la verdad de las religiones puede reformularse en términos que desbordan la evaluación epistémica de las creencias: ¿Cuáles son los rasgos de una vida en relación con la verdad divina? Esta pregunta muestra que no solo las creencias religiosas pueden ser verdaderas o falsas, sino las formas de vida, las actitudes y las acciones basadas e inspiradas en ellas. Esto suena extraño para las teorías tradicionales de la verdad, para las cuales "el portador de verdad" se ubica siempre del lado de las creencias, las proposiciones o las representaciones; pero es una consecuencia del carácter relacional y vivencial de la verdad religiosa que -como hemos dicho- rebasa, aunque no niega, lo proposicional.

\section{Conclusión: la verdad como relación y el "prejuicio" judeo-cristiano de estos criterios}

La pregunta acerca de los rasgos que caracterizan una vida en relación con la verdad divina, que constituye la especificación de nuestro segundo criterio de verdad, debe ser respondida por cada tradición en sus propios términos y luego puede ser confrontada en el encuentro con los otros en el diálogo interreligioso. Para el cristianismo esto puede contribuir a que logremos vivir a profundidad, como don y vocación, la tensión entre su pretensión de universalidad y su carácter histórico.

La plenitud de la verdad recibida en Jesucristo no da a cada uno de los cristianos la garantía de haber asimilado plenamente tal verdad. En última instancia, la verdad no es algo que poseemos, sino una persona por la que tenemos que dejarnos poseer. Se trata, así, de un proceso sin fin. Aun manteniendo intacta 
su identidad, los cristianos han de estar dispuestos a aprender y a recibir, por mediación de los demás, los valores positivos de sus tradiciones. De esta manera, el diálogo puede hacerles vencer sus prejuicios inveterados, revisar sus propias ideas y aceptar que a veces la comprensión de su fe sea purificada. ${ }^{30}$

Al enfatizar en este carácter relacional y vivencial de la verdad cristiana, el papa Francisco señala, en su carta de respuesta al periodista italiano Eugenio Scalfari, en el 2013:

...no hablaría, ni siquiera para quien cree, de verdad "absoluta", si se entiende absoluto en el sentido de inconexo, que carece de cualquier tipo de relación. Para la fe cristiana, la verdad es el amor de Dios por nosotros en Jesucristo. Por tanto, jla verdad es una relación! De hecho, todos nosotros captamos la verdad y la expresamos a partir de nosotros mismos: desde nuestra historia y cultura, desde la situación en que vivimos, etc. Eso no quiere decir que la verdad sea variable y subjetiva, todo lo contrario. Más bien indica que se nos da siempre y solo como camino y vida. ¿No dijo el mismo Jesús: "Yo soy el camino, la verdad y la vida"? Con otras palabras, la verdad, siendo, en definitiva, una sola cosa con el amor, requiere humildad y apertura para buscarla, acogerla y expresarla. Por tanto, es necesario ponerse de acuerdo en los términos, y quizás, para salir de los atolladeros de la contraposición... absoluta, replantear en profundidad la cuestión. ${ }^{31}$

Estas dos citas muestran hasta qué punto el carácter relacional de la verdad está ligado con su historicidad. La capacidad de apertura a lo nuevo y la conciencia de que no podemos poseer la totalidad de la verdad, ni reducir totalmente al otro a nuestras creencias previas, son rasgos propios de toda auténtica relación personal. La noción hebrea de verdad, emeth, con su referencia a la estabilidad y la firmeza de las cosas, las palabras y las personas en las que se puede confiar, permite captar claramente el carácter relacional e histórico de la verdad.

Como ha mostrado Pannenberg, este sentido de lo verdadero está ausente de la comprensión griega de la verdad como alétheia, es decir, como el desocultamiento del modo de ser de las cosas, de su esencia eterna e inmutable, que se encuentra siempre ahí, presente detrás de las apariencias propias de las impresiones sensoriales, y es asequible solo a la razón ${ }^{32}$.

A diferencia de esta comprensión griega y de sus desarrollos en el pensamiento occidental, la noción de emeth implica que la constancia y permanencia de lo que

\footnotetext{
${ }^{30}$ Consejo Pontificio para el Diálogo Interreligioso, "Diálogo y anuncio", 49.

${ }^{31}$ Francisco, "Carta del santo padre Francisco al periodista italiano Eugenio Scalfari del periódico $\mathrm{La}$ Repubblica, 13 septiembre 2013".

32 Pannenberg, "What is Truth?", 4ss.
} 
es verdadero requiere ser comprobada siempre de nuevo, en cada nueva situación contingente, y no puede garantizarse tan solo deductivamente. "La verdad de Dios se prueba a sí misma por el hecho de que solo él es capaz de garantizar la estabilidad" 33 tanto del orden creado (Sal 98; 100,5; 115,1) como de la vida de las personas, al ser su escudo y liberador (Sal 91; 103,17; 117; 138; 143).

De este modo, la verdad de Dios constituye un tipo de experiencia histórica que comprende dos elementos: por un lado, la constatación de sus manifestaciones puntuales en medio de los eventos contingentes que gradualmente forman el pasado y de los que se tiene recuerdo; por el otro, la confianza y la esperanza de que su fidelidad se manifestará de nuevo. En este sentido, la comprobación de la verdad de Dios, esto es, su fidelidad y amor, no es resultado de una operación racional que desoculta la esencia de las cosas y demuestra su carácter absoluto e inmutable. "No es el resultado de la necesidad lógica, de que lo que es, es” ${ }^{34}$. Se trata más bien de la experiencia de descubrir en el pasado su acción salvadora y desde ahí vivir cada presente abriéndose al futuro con confianza. Así, la experiencia de la verdad de Dios es ya de suyo la experiencia de la fe que puede afirmar:

Fijaos en las generaciones antiguas y ved:

¿Quién confió en el Señor y quedó defraudado?

¿Quién perseveró en su temor y fue abandonado?

¿Quién le invocó y fue desatendido? (Si 2,10)

Sin embargo, ¿acaso este tipo de experiencia de la verdad, como la historia de la relación con Dios, no es propia únicamente de las tradiciones judeo-cristianas y, si acaso, por extensión, de las tradiciones abrahámicas en general, de modo que basar en ella el criterio de la verdad para el diálogo interreligioso resultaría injusto con otras religiones que no tienen una visión de mundo histórica, ni experimentan lo divino como una persona con la que se pude estar en relación? Considero que es posible encontrar elementos análogos o más bien equivalentes homeomórficos-como los llama Raimon Panikkar ${ }^{35}-$, de esta experiencia en otras tradiciones.

\footnotetext{
${ }^{33}$ Ibíd., 6.

${ }^{34}$ Ibíd., 8.

${ }^{35}$ En la hermenéutica intercultural de Panikkar, la comprensión del otro no se basa en la búsqueda de términos en su lenguaje o cosmovisión que puedan tener el mismo significado que en la propia, ni en términos que puedan tener un significado simplemente análogo. "El homeomorfismo significa más bien que las nociones desempeñan roles equivalentes, que ocupan espacios homólogos dentro de sus respectivos sistemas. El homeomorfismo es quizás un tipo de analogía existencial-funcional" (Panikkar, The Intrareligious Dialogue, 67).
} 
No es este el espacio para explorar tal hipótesis. Más bien quiero señalar que es legítimo y necesario que cada tradición particular construya, a partir de sus propios recursos conceptuales y experienciales, los criterios que pueden guiar a sus participantes en el encuentro con los miembros de otras tradiciones religiosas. Por supuesto, eso no significa que sea válido pretender que los compañeros en el diálogo acepten y utilicen ellos mismos tales criterios, sino más bien que cada uno asuma la tarea de proponer sus propios criterios a partir de sus sistemas religiosos. ¿De dónde más puede proceder la motivación y la orientación básica para el diálogo interreligioso?

\section{Bibliografía}

Celam. V Conferencia del Episcopado Latinoamericano y del Caribe. Documento de Aparecida. Bogotá: San Pablo, 2007.

Clayton, Philip. Explanation from Physics to Theology. An Essay in Rationality and Religion. New Haven (CT)-London: Yale University Press, 1989.

Cobb, John. "Beyond 'Pluralism”". En Christian Uniqueness Reconsidered, editado por Gavin D’Costa, 81-95. Maryknoll (NY): Orbis, 1990.

Comisión Teológica Internacional. "El cristianismo y las religiones (1996)". Vatican, http://www.vatican.va/roman_curia/congregations/cfaith/cti_documents/ rc_cti_1997_cristianesimo-religioni_sp.html (consultado el 2 de septiembre de 2016)

Concilio Vaticano II. Documentos completos. Bogotá: San Pablo, 2006.

Consejo Pontificio para el Diálogo Interreligioso. "Diálogo y anuncio (1991)”. Vatican, http://www.vatican.va/roman_curia/pontifical_councils/interelg/documents/ rc_pc_interelg_doc_19051991_dialogue-and-proclamatio_en.html (Consultado el 2 de septiembre de 2016)

Coward, Harold. Pluralism. Challenge to World Religions. Maryknoll (NY): Orbis, 1985.

D’Costa, Gavin (ed.). Christian Uniqueness reconsidered. Maryknoll (NY): Orbis, 1990.

Dupuis, Jacques. Hacia una teología cristiana del pluralismo religioso. Santander: Sal Terrae, 2000.

Escuela Bíblica de Jerusalén. Biblia de Jerusalén. Bilbao: Desclée de Brouwer, 2009.

Francisco. "Carta del santo padre Francisco al periodista italiano Eugenio Scalfari del periódico La Repubblica, 13 de septiembre de 2013". Vatican, https:// w2.vatican.va/content/francesco/es/letters/2013/documents/papa-francesco_20130911_eugenio-scalfari.html (consultado el 2 de septiembre de 2016). 
. Exhortación apostólica "Evangelii gaudium". Bogotá: Paulinas: 2013.

Gilkey, Langdon. "Pluralism and Its Theological Implications". En The Myth of Christian Uniqueness, editado por John Hick y Paul Knitter, 37-50. Maryknoll (NY): Orbis, 1987.

Gómez, Carlos Miguel. Diálogo interreligioso: el problema de su base común. Bogotá: Universidad del Rosario, 2008.

. "Fe y conocimiento. Investigación sobre la función epistémica de la creencia religiosa”. En ¿Ciencia o religión? Exploraciones sobre las relaciones entre fe y racionalidad en el mundo contemporáneo, editado por Luis Fernando Múnera, Raúl Meléndez y Carlos Miguel Gómez, 19-44. Bogotá: Editorial JaverianaEditorial Universidad del Rosario, 2017. . Interculturaliry, Rationality and Dialogue. In Search for Intercultrual Argumentativa Criteria for Latiamerica. Würzburg: Echter, 2012.

Hick, John. An Interpretation of Religion. New Haven (CT): Yale University Press, 2004. . Problems of Religious Pluralism. London: McMillan, 1985.

Hume, David. Investigación sobre el entendimiento humano. Bogotá: Norma, 1998.

Iglesia Católica. "Catecismo de la Iglesia Católica". Vatican, http://www.vatican.va/ archive/catechism_sp/index_sp.html (consultado el 9 de septiembre de 2016).

Knitter, Paul. One Earth Many Religions: Multifaith Dialogue and Global Responsibility. Maryknoll (NY): Orbis, 1995.

McGrath, Alister. A Scientific Theology: Nature. London: T\&T Clark, 2006. . Surprised by Meaning. Science, Faith and How We Make Sense of Things. Louisville (KY): WJK Press, 2011.

Múnera, Luis Fernando; Raúl Meléndez y Carlos Miguel Gómez (eds.). Ciencia y creación. La investigación cientifica de la naturaleza y la visión cristiana de la realidad. Santander- Bogotá: Sal Terrae-Editorial Javeriana (en proceso de publicación).

Panikkar, Raimon. The Intrareligious Dialogue. Revised Edition. New York (NY): Paulist Press, 1999.

Pannenberg, Wolfhart. "Is There Any Truth in God-Talk? The Problem of Theological Statements from the Perspective of Philosophy of Science". En The Historicity of Nature. Essays on Science and Theology, editado por Niels Henrik Gregersen, 11-22. West Conshohocken (PA): Templeton Foundation Press, 2008. 
. "What is Truth?" En Basic Questions in Theology. Vol. II, 1-27. Philadelphia (PA): Fortress Press, 1971.

Rorty, Richard. Contingencia, ironía y solidaridad. Barcelona: Paidós, 1991.

Tamayo, Juan José. Fundamentalismos y diálogo entre religiones. Madrid: Trotta, 2004.

Teixeira, Faustino. Teología de las religiones. Una visión panorámica. Quito: Abya Yala, 2005.

Twiss, Summer. "The Philosophy of Religious Pluralism: A Critical Appraisal of Hick and His Critics". En The Philosophical Challenge of Religious Diversity, editado por Philip Quinn y Kevin Meeker, 67-98. New York (NY): Oxford University Press, 2000.

Wolterstorff, Nicholas. "Are Religious Believers Committed to the Existence of God?" En Practices of Belief. Selected essays. Vol. 2 Nicholas Wolterstorff, editado por Terence Cuneo, 350-371. New York (NY): Cambridge University Press, 2014. 